\title{
Linking Adaptation and Mitigation Toward a Resilient and Robust Infrastructure Sector in Kenya
}

\author{
Onkangi Ruth, David Lagat, and Ondari Lilian
}

\section{Contents}

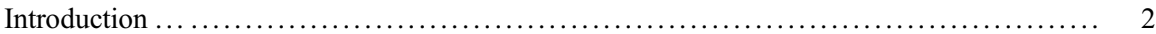

Climate Change Issues Affecting the Built Environment $\ldots \ldots \ldots \ldots \ldots \ldots \ldots \ldots \ldots \ldots, 5$

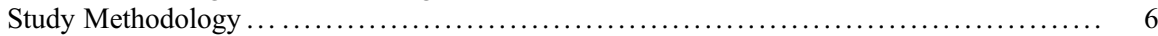

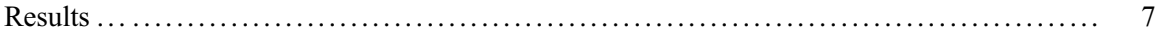

Climate Change Mitigation and Adaptation Interventions in Nairobi City ............ 7

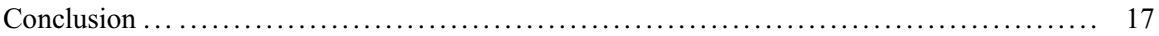

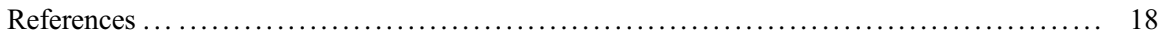

\section{Abstract}

Sustainable city is an oxymoron to many especially in developing nations where the ever extending urban fabric has consequently degraded natural habitats, altered species composition, changed energy flows, and immensely affected biogeochemical cycles. This dims the vision of meeting the present needs with a nondecreasing level of well-being while not compromising that of the future

This chapter was previously published non-open access with exclusive rights reserved by the Publisher. It has been changed retrospectively to open access under a CC BY 4.0 license and the copyright holder is "The Author(s)". For further details, please see the license information at the end of the chapter.

\section{O. Ruth $(\bowtie)$}

National Construction Authority, Nairobi, Kenya

e-mail: konkangi@gmail.com

D. Lagat

Construction Research and Business Development Department, National Construction Authority, Nairobi, Kenya

e-mail: dvdlagat@gmail.com

O. Lilian

ClayCo, Chicago, IL, USA

e-mail: nyanchyond@gmail.com 
generations to meet theirs. Nairobi as other cities in peer nations is associated with socioeconomic vulnerabilities as well as visible and "invisible" ecological problems such as pollution, climate change, spatial competition, dependency in natural capital use, and congestion. Nevertheless, this is uniquely both a problem and a solution.

Nairobi has grown from a small railway station at the turn of the twentieth century to one of Africa's largest cities. With this growth, comes an oversized ecological footprint and complex challenges of stresses and shocks. Infrastructure development in developing nations is gaining momentum. It is one of the development indicators and a major contributor to the GDP. However, it is very vulnerable financially and functionally to extreme weather events such as intense and prolonged periods of rainfall, inundation, low retreating rates of flood waters, increased temperatures, and unpredictable wind patterns. This study sought to establish the level of integration of adaptation and mitigation measures to climate change in selected infrastructure projects. It further evaluates the performance of key action plans, projects, and efforts made to enhance resilience to climate change. The study supports the integration of broad investment flows instead of the project-by-project approach.

\section{Keywords}

Climate change $\cdot$ Adaptation $\cdot$ Mitigation $\cdot$ Infrastructure $\cdot$ Policy $\cdot$ Cities

\section{Introduction}

There has been increased deliberate effort to build the technical capacity within cities in developing countries to combat climate change through developing long-term national climate action plans thus creating an enabling environment for low carbon development. However, mitigation of climate change has received more financial, technical support, and mention in policy documents compared to adaptation. Climate change is a current phenomenon and no longer an anticipated occurrence. Developing countries are very vulnerable to climate change and a lot of natural resource-driven economic development is ongoing. Therefore, there is need to embrace low emission development pathways which integrate climate adaptation and mitigation activities for future proofing of the built environment.

According to UNEP, sixty-six percent (66\%) of infrastructure in developing countries is yet to be built. This is an opportunity to make carbon-efficient cities a reality and not just rhetoric. This uniquely makes developing world cities both a challenge and a solution to climate change. With this unique opportunity to have mitigation and adaptation march in lockstep as well as avert high carbon stranded assets in the future, emerging economy cities need to gravitate toward sustainable development and keep their carbon footprint low. Embracing a responsible resource consumption and production approach will not only avoid locking in of unsustainable lifestyles and technologies but will also concurrently support both adequate mitigation and adaptation measures to climate change. 
Linking adaptation and mitigation is imperative if developing countries are to keep their emissions low in the face of future developments and if the overall carbon emissions globally are to be reduced to safe levels in the near future.

Developing countries as far as infrastructure is concerned need to be climate wise if they aim to avert retrogression (economically and socially). Being climate wise in the built environment means adding the data layer to planning and designing, conducting mapping of vulnerability for infrastructure assets, as per location, exposure level to climatic changes, sensitivity, type of asset, design life and its adaptive capacity to support adaptation actions, and disaster preparedness as the built environment expands with economic growth. Also, industry professionals need to have climate change adaptation and mitigation knowledge to incorporate it in design of current and future projects.

This can be achieved through integration of climate change adaptation and mitigation knowledge in the curriculum of construction industry professionals. Conducting research on suitability of materials for adaptation and mitigation and offering a knowledge platform for the same will support timely climate proofing for the ongoing delicate economic progress.

In addition, adaptation and mitigation can march in lockstep to enhance resilience through broad investment flows in policy, education, and planning by review of physical planning policies to support a negative feedback loop in growth and expansion. Planning needs to precede infrastructure development (Yigitcanlar and Kamruzzaman 2015). Government should not authorize any project in an area without prior and authorized physical planning. Further, every mega development project needs to have reliable enforceable measures stated in the Strategic Environment Assessment Study report to counter the positive feedback loop associated with the project. Further, Nairobi can adopt a form-based code that encourages building out instead of uncontrolled infill development. Incorporating population growth data, flood estimation in the design of roads, culverts, and stormwater drainage systems as well as wastewater infrastructure enacting policy to support uptake of protective engineering in the coastal area.

The National adaptation and mitigation plans need to have targets attached to sector-specific responses to climate change. This will support a coordinated response to climate change that will favor integration of broad investment flows instead of the project-by-project approach (silo responses).

The rapid growth and extending urban fabric in Nairobi bring with it an oversized ecological footprint and complex challenges including increased natural capital dependency more spatial competition and congestion. This rapid unsustainable development translates to rapid carbonization of developing country economies.

Environmental degradation in Nairobi has majorly and anecdotally manifested through:

1. Reduction in green spaces, over the years, as vegetation and trees are cleared to pave way for construction (see an attached satellite map in Fig. 1 showing the changes that have occurred over years in Kilimani area and around Nairobi National park) (which translates to loss/reduction of carbon sinks). 


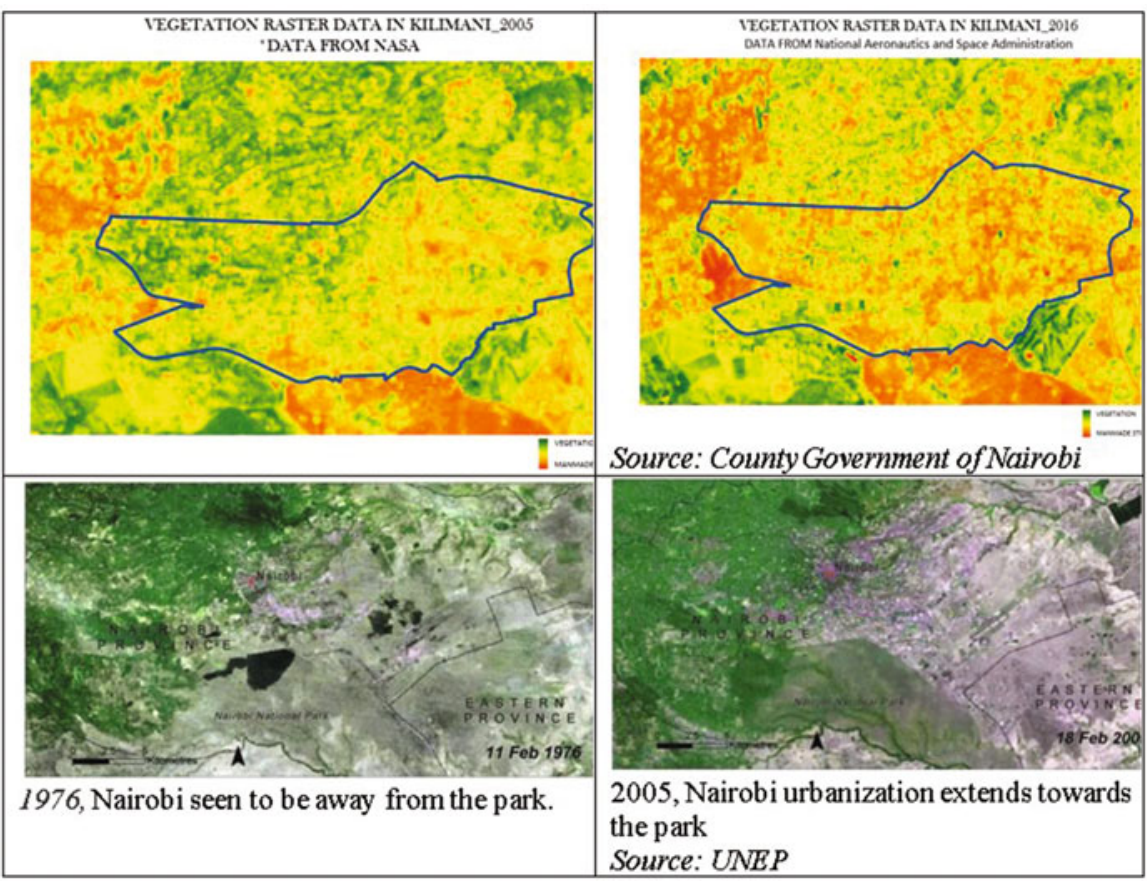

Fig. 1 Spatial representation of decreasing green spaces in Nairobi

2. Shrinking and polluted blue features.

3. Increased use of motor transport and traffic congestion.

4. Sudden and rapid decrease of groundwater table due to less percolation as most surfaces are paved, and extraction rate of water exceeds recharge rates.

5. Flooding, water, noise, and air pollution.

6. Inadequate waste management-illegal dumping and inability to collect and dump at the designated place. The waste finds its way to drains hence causing blocking of stormwater drains and natural stream channels.

7. Heat island effect and increased energy use.

Despite devolution of the Government in Kenya, Nairobi's urban population is far from taking a plunge. Therefore, problems plaguing the city of Nairobi now need a lasting solution that will be immune to climatic changes for continuity and quality standard survival of progeny.

According to Kenya urbanization review conducted by World Bank, urban areas in Kenya at the moment play host to over ten million Kenyans. Nairobi hosts the majority with over four million people. World Bank estimates that by 2050 as many as 48.46 million people in Kenya will be living in cities this is equivalent to the country's entire present population (World Bank 2016). Rural to urban migration is informing the rapid expansion, however, the population of Kenyans migrating to cities is of a high fertility rate; this means urban population will continue to increase 
amid efforts to decentralize systems and discourage rural to urban migration (Hope 2012).

Consequently, as a proactive remedy, sustainable development is to be inculcated here and now in the face of future growth and expansion. Linking adaptation and mitigation in Nairobi will set precedence in other emerging urban areas as well as in two other developing cities in Kenya like Mombasa and Kisumu. If unsustainable urbanization as of the moment in Nairobi continues then the problem will be repeated in emerging urban areas hence weakening national future proofing efforts and further enhancing vulnerability. The reverse is also true; a success story of linking adaptation and mitigation to climate change in Nairobi will reverberate in the entire urban ecosystem of the country. This paper evaluates level of integration of adaptation and mitigation measures to climate change in infrastructure projects (in three areas: climate data integration in infrastructure development, water security, and gray to green infrastructure ratio) in Kenya's capital as a partial and major contributor to the shift to sustainable city status.

\section{Climate Change Issues Affecting the Built Environment}

According to the Intergovernmental Panel for Climate Change (IPCC) GCMs (Global Circulation Models), Kenya is likely to experience adverse climate changes between the late 2020s and 2100. The GCMs projections based on a grid resolution of $200 \times 200 \mathrm{~km}$ though having not included altitude modifications indicate that both rainy seasons are likely to become wetter especially the short rains that normally fall between October and December every year. Increased rainfall intensity events will lead to more flooding events in frequency and severity. Sea level rise will also have $17 \%$ of Mombasa (Kenya's second largest city) flooded.

The northern part of Kenya as per the GCMs will have $40 \%$ rainfall increases by 2100 . By 2020 s temperature are postulated to rise by $1{ }^{\circ} \mathrm{C}$ and $4{ }^{\circ} \mathrm{C}$ by 2100 (Parry et al. 2012).

These climatic changes will affect not just biodiversity, agriculture, and health aspects of the populace but infrastructure is vulnerable as well. By the fact that infrastructure underpins every sector, it is crucial to future proof assets to reinforce the efforts in other sectors to combat climate change for holistic resilience.

The infrastructure sector is vulnerable and responsible for climate change (to a large extent). Overall, the construction industry is responsible for one third of greenhouse gas (GHG) emissions. And depending on how you apportion it, buildings are contributing to almost half of GHG emissions.

Changes associated with climate changes are forecasted to contribute to degradation of infrastructure and building materials (Wilby 2007; Onkangi et al. 2019). Water availability is likely to affect demand and supply especially in prolonged dry spells; this can affect construction projects as they are heavily reliant on water. Increased precipitation will affect stormwater drainages, load, wastewater treatment systems and road networks causing project delays and reducing lifetime of infrastructure (Nelson et al. 2009; Onkangi et al. 2019). Cascading of failures due to linkages of infrastructure will have a knock-on effect on operations and the 
economy. Mitigation of and adaptation to climate change in the building sector are imperative (Onkangi et al. 2019).

Infrastructure more so in urban areas is interdependent especially through the water and wastewater systems as well as the drainage system. Infrastructure-toinfrastructure ties are also very present (water or non-water); therefore, weatherrelated disruptions whose genesis is hydrologic floods and intense precipitation can reverberate through the entire system. Therefore, management practices in one infrastructure will impact another (Onkangi et al. 2019; Wilbanks and Fernandez 2014).

The building sector like other sectors needs to play its part in lowering global temperatures to below $2{ }^{\circ} \mathrm{C}$ above preindustrial levels as agreed in the Paris Agreement 2015 in which Kenya is signatory to. The Building's day in the COP 21 gave birth to a commitment among participating nations that the construction sector will reduce emissions by $84 \mathrm{GtCO} 2$ by 2050 (Paris Agreement 2015).

Through "adaptable architecture" or "adaptable buildings," both adaptation and mitigation can be adequately addressed in the built environment. Mitigation can be addressed through adaptation. "Adaptable architecture" or "adaptable buildings" are "concepts that feature flexibility in the function, physical form or experience in buildings along with a desire to develop systems for mass customization as well as pre-fabrication of building components with the end-use of buildings in mind" (Dave et al. 2016).

Where there is adequate planning, infrastructure informs cities. Greening infrastructure is the ignition key of a sustainable city. Nonetheless, mitigation and adaptation efforts in developing countries are biased to agriculture, human health, and biodiversity. Infrastructure is yet to be looped in adequately. It is crucial to ensure food security in the future, but if connectivity in the transport and communication is lost due to climate and weather-related interruptions then the farmer's produce fails to reach the market, and food security is jeopardized.

People spend $90 \%$ of the time in buildings, when adaptation to climate change is not incorporated in design and implementation then challenges due to extreme weather events compromise user comfort and threaten overall well-being (Klepeis et al. 2001). The research on building failures in Kenya indicated that more collapses happened in the rainy season. With climate projections indicating increased rain intensity and flash flooding in the future, a major threat looms for nonresilient assets whose numbers are evidently not few neither are the users (NCA 2017).

\section{Study Methodology}

Through desktop study and literature review, criteria for evaluating mitigation and adaptation measures shown in Fig. 2 were adopted. In the period of August 2016 and November 2016, a descriptive survey tool of 72 structured questionnaires assessing the measure was administered to contractors, engineers, architects, quantity surveyors, construction firms, project managers, and construction managers. 51 questionnaires dully filled were collected giving a response rate of $71 \%$. Further, desktop 
Infrastructure Adaptation

-Policy and legislation on adaptation of infrastructure to Climate Change (CC)

- Infrastructure climate change adaptation plan

- Incorporation of adaptation to $\mathrm{CC}$ in the Building code

- Capacity building of industry professionals on adaptation to $\mathrm{CC}$

- Integration of adapation measures to climate change

- Political goodwill

- City specific Climate data availability

- Level of integration of climate data in design and construction

- Disaster response system for infrastructure

- Level of integration of the data layer in infrastructure development

\section{Infrastructure Mitigation}

- Sector specific policy and legislation on mitigation

- Infrastructure climate change mitigation plans

- Perceptions and attitudes to incorporating mitigation measures

- Sectoral mitigation targets

- Grey to green infrastructure ratio

- Operational Knowledge

- Commitments to Multilateral agreements on sustanaible and climate resilient cities

- Level of integration of climate data in design and construction

Fig. 2 Adaptation and mitigation evaluation criteria

study, observation, and assessment of infrastructure more so where failures were reported yield information to complement the feedback from questionnaires on integration of mitigation and adaptation. These findings gathered from the expert community were analyzed using SPSS, and the evaluation forms the bulk of this paper.

\section{Results}

\section{Climate Change Mitigation and Adaptation Interventions in Nairobi City}

\section{Gray to Green Infrastructure Ratio}

The green infrastructure concept is an integrated approach that connects services, ecology, land use, and heritage. This "joined up" thinking delivers critical environmental services presenting a sustainable alternative to growth and development while upholding both mitigation and adaptation measures. Green infrastructure is multifunctional compared to gray infrastructure that is mostly single function. Both are critical and investment in both should be simultaneous. With decreasing green spaces, Nairobi has increasingly experienced the harshness associated with their reduction and loss.

Nairobi's builtscape was previously nested in green spaces. The world's only urbanite national park, an array of city parks, botanical gardens, and arboretum earned Nairobi the title "green city in the sun." However, the spaces have been decreasing as shown in Fig. 1.

The new construction projects including roads in Kenya such as Thika road have a high gray to green infrastructure ratio, see Fig. 3 . 


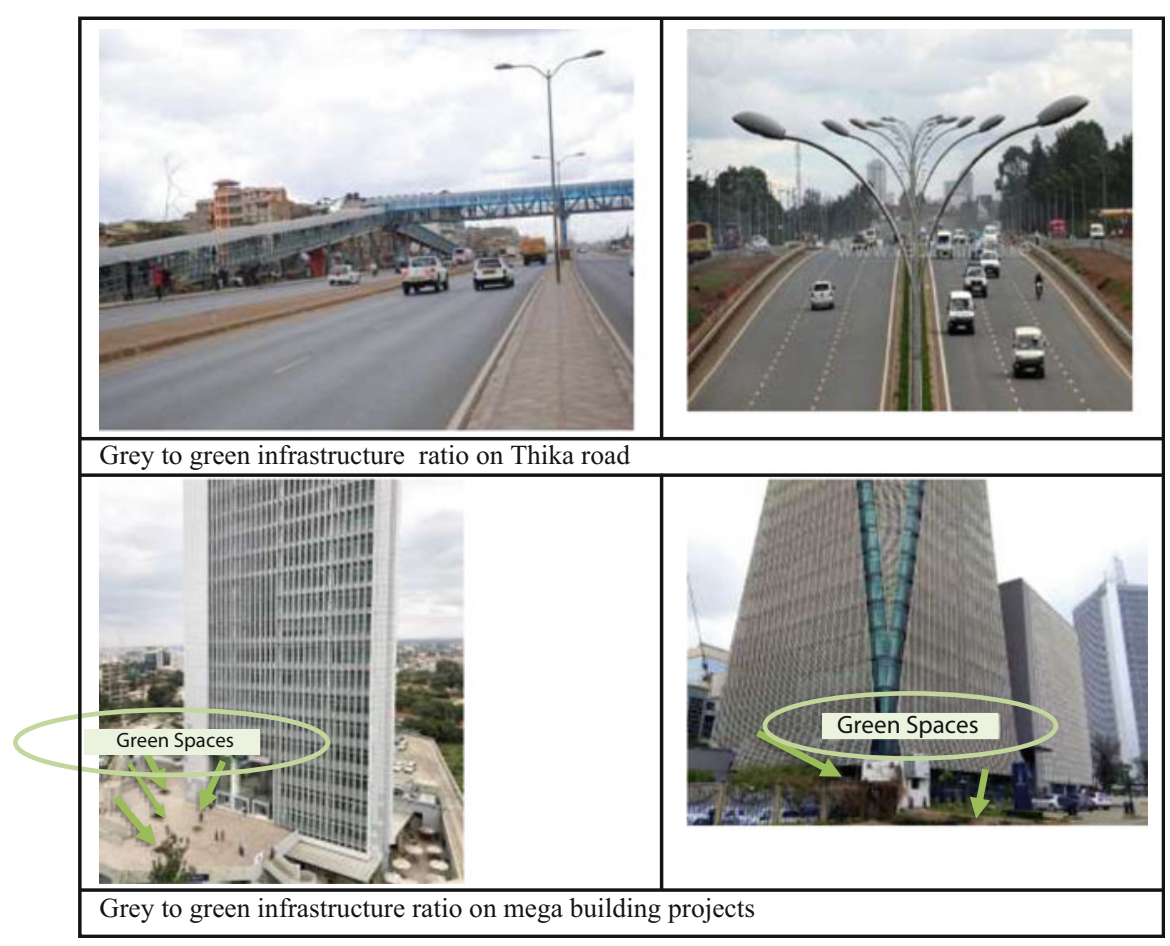

Fig. 3 Green to gray infrastructure ratio in mega projects

As the urban fabric continues to extend, green spaces continue to shrink (see Fig. 1). The concrete jungle is gaining dominance. In many Environmental Impact Assessment project reports, developers commit to landscaping and site restoration as far as possible. In the Environment Impact Assessment (EIA) reports, each project needs to state and commit to adaptation and mitigation measures adopted to combat climate change. But there are no set targets of the percentage of the project area that should be landscaped in the EIA reporting. This indirectly encourages the high gray to green infrastructure ratio. As seen in Fig. 3, lofty expansive buildings have dots of green spaces as part of landscaping and for aesthetics.

However, there is lack of targets on what percentage of the project area should have open spaces. Neither is there a policy push to have pervious spaces given a percentage priority in open space management. To create space for parking, many of the spaces surrounding are highly paved. The green to gray ratio in projects needs to be given a baseline per square meters of gray space; there should be greening of an equivalent space to counter negative impacts guided by adaptation and mitigation targets. The Government is yet to offer incentives to encourage sustainable construction to counter high paving of buildings. Policy to encourage silo parking and green roofing is a better option. 


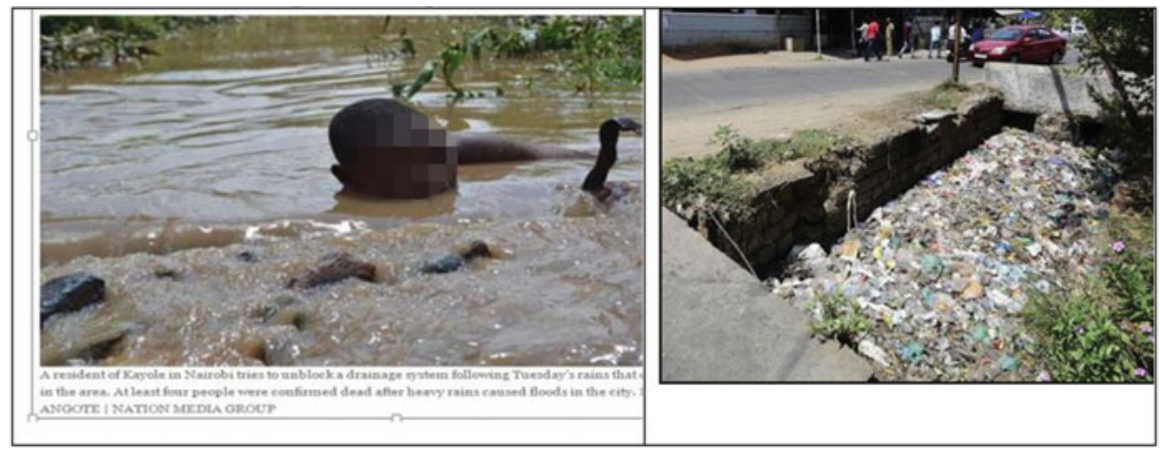

Fig. 4 Poor solid waste management has aggravated inundation in Nairobi

Illegally, numerous projects more so in low income neighborhoods construct beacon to beacon. And in upmarket areas, service paving is widespread. Increased paved surfaces ushered by rapid urbanization with gray infrastructure has aggravated inundation as flood waters flow rapidly to rivers rather than being slowed by natural means through underground seepage and uptake by vegetation (green infrastructure). In addition, natural and manmade channels have been obstructed due to poor management of solid waste as shown in the Fig. 4.

The old concept of draining water away from cities through stormwater collection is not only contributing to pollution of water bodies but water insecurity in the face of climate change as aquifers are not recharging at the same rate as extraction. Population explosion has also overwhelmed the drainage system and increased urbanization of river catchment areas through illegal settlements and encroachments (Douglas et al. 2008). Consequently, small downpours translate to flash floods due to surface runoff from the paved surfaces and drains. Wastewater systems get overwhelmed, and sewage overflows are a common site. Further, in cases where rivulets and stormwater flows through a series of concrete passages and culverts, they are unable to adjust to rain intensity and frequency as natural streams do. This is largely attributed to lack of incorporation of the demographic data layer in city planning, infrastructure design, and construction.

\section{Depleting Aquifers}

With the heavy downpour in certain periods of the year, the water table in Nairobi is still receding at a fast rate threatening subsidence of buildings. According to numerous studies and the National Environment Management Authority, increased hard paving and construction of buildings has reduced percolation to recharge the groundwater. Vegetation, soft landscaping, or pervious paving systems are crucial for recharge and cooling. However, wide hard paving as is the case in Nairobi at the moment causes most of the rainwater flows as surface runoff and is rapidly conducted to streams and rivers due to a high gray to green infrastructure ratio.

As the built environment has extended, the groundwater level has decreased, this is evidenced in various studies. Through the years with growing demand the number 
of boreholes sunk in Nairobi has increased drastically from 2 in 1927 to over 2500 in the year 2009 (Mathu et al. 2014). Also, the average depth of the water table has alarmingly decreased. In 1920s boreholes were sunk to a depth of only 20-22 m. As of 1950, the groundwater level was $80 \mathrm{~m}$ deep while in 1996 it was about $140 \mathrm{~m}$. This has been receding further at a rate of $1.8 \mathrm{~m}$ per month or even faster (Mathu et al. 2014; Olingo 2011; Foster and Tuinhof 2005).

The study by Mathu, Onyancha, Mwea, and Ngecu (2014) on "Effects of Drilling Deep Tube Wells in The Urban Areas of Nairobi City, Kenya" where the researchers used Surfer 9 software to analyze level of groundwater static variations in space and time in boreholes between 1927 and 2009, established that "groundwater rest levels have dropped with an average of $79 \mathrm{~m}$ in the last 80 years and a probable settlement of $0.34 \mathrm{~m}$ to $5.9 \mathrm{~m}$ could result from groundwater depletion from aquifers and clay aquitards over a long period of time. This should serve as a wakeup call to put up measures that can mitigate subsidence and the related consequences in Nairobi City." The study also verified that $67 \%$ of the drop in groundwater rest levels has happened in the last two decades with sinking of boreholes in thousands (Mathu et al. 2014). The law requiring boreholes to be sunk at least $100 \mathrm{~m}$ apart is also not observed (Kenyan Parliament 2016). There is a continued scramble and siphoning of the Nairobi groundwater. The biophysical transformation due to urban sprawl is not making it better due to little recharge.

\section{Heat Island Effect}

The heat island effect serves as the basic climate response to urbanization. Due to Nairobi's location at the tropics, the heat island effect is not as significant as it is in cities located in the temperate regions. "An investigation of urban heat island phenomenon in Nairobi" by Reginald Ambona over the period of 1991-2011 using the wind rose technique to examine presence of the heat island plume confirmed that Nairobi experiences heat island effect though not large enough (Amboga 2013). This was similarly observed in an earlier study which warned that with current trends of population increase, greater motor vehicle density and higher industrialization and urban spread, the anthropogenic waste heat ejection would be large enough to modify the heat balance of Nairobi city appreciably by the year 2030 (Opijah et al. 2008).

In 2009, Makokha and Shisanya found that cooling and warming rates were highest at the suburban study site and lowest at the urban canyon study site. The built environment in the study sites explained the differential cooling and warming rates. The study recommended proper planning of the built environment to ameliorate the problem of excessive nocturnal heat loads within the built environment (Makokha and Shisanya 2010).

A similar study by Silas Owiti in 2016 indicated that there is a growing distribution of heat islands in Nairobi. There was negative correlation between land surface temperature (LST) and normalized difference vegetation index (NDVI) implying that vegetation alleviated the heat island effect, while the positive correlation between LST and urbanization indicated that the urbanization increases the heat island effect. Owiti's study concluded that with the rate of urbanization, the 
distributed heat island effect, with time will conglomerate into a large heat island in the city (Owiti 2016).

These results are attributed to infill development as well as urban sprawl in Nairobi which is causing enormous vegetation loss. Impervious surfaces such as buildings, parking spaces, and tarmac roads have affected the heat balance regulated by the natural ecosystem.

Passing environmental laws, policies, action plans that are definite and give project specific binding targets on mitigation will help foster sustainability. In addition, project environmental audit reports should include mitigation and adaptation achievements and opportunities. Providing a business case for integrating climate action in city projects as well as creating a knowledge platform and increase awareness on adaptation and mitigation for infrastructure projects will support adoption of environmental stewardship in the built environment in Kenya.

\section{Transport Infrastructure}

The 1997/1998 El Niño rains are estimated to have caused the country's roads, water supply infrastructure, buildings, and telecommunication infrastructure damage of US\$0.8-1.2 billion equivalent to $11 \%$ of Kenya's GDP (MoE 2010, 2013). "Other losses amounting to US\$9 million arose from flooding, property destruction, soil erosion, mudslides and landslides, surface and groundwater pollution and sedimentation of dams and water reservoirs" (MoE 2013).

The National Climate Change Action Plan 2013-2017 directs that "new investments in infrastructure must consider expected changes in temperature and precipitation." According to the Plan for a low carbon climate-resilient pathway, infrastructure should be "climate proofed" the plan elaborates on climate proofing to mean "designed, constructed and operated in a way that accounts for anticipated risks and opportunities that result from climate change, ensuring that infrastructure investments are not compromised in the future." Further, it states the need to account for sea levels rise in infrastructure, port facilities, roads, railways, and bridges.

However, emerging from this study is that there is low integration of climate data in new infrastructure development. The sector is yet to adopt action plan measures to enhance resilience, ongoing, and newly completed projects use historical data, but future predictions are not factored in. This is attributed to level of availability of meteorological (met) data. Many study respondents indicated that they do not have access to meteorological data and that which is available is expensive thus adding to the project costs.

A price-based economy is seemingly not supporting many key interventions that could be costly in the short term but avert bigger costs in the long term. Also, the met stations are few, monitor particular elements and inconsistencies in data records affect reliability.

The Government is building a sea wall to protect a monumental site (Fort Jesus) from sea level rise. The reactive adaptation to sea level rise on this centuries old monument is a step in the right direction; however, new developments are not taking up proactive adaptation measures against sea level rise as seen in the new Mombasa road by the seaside (see Fig. 5). Prioritizing maintenance of infrastructure in vulnerable areas, incorporating climate change in maintenance, and retrofitting of 


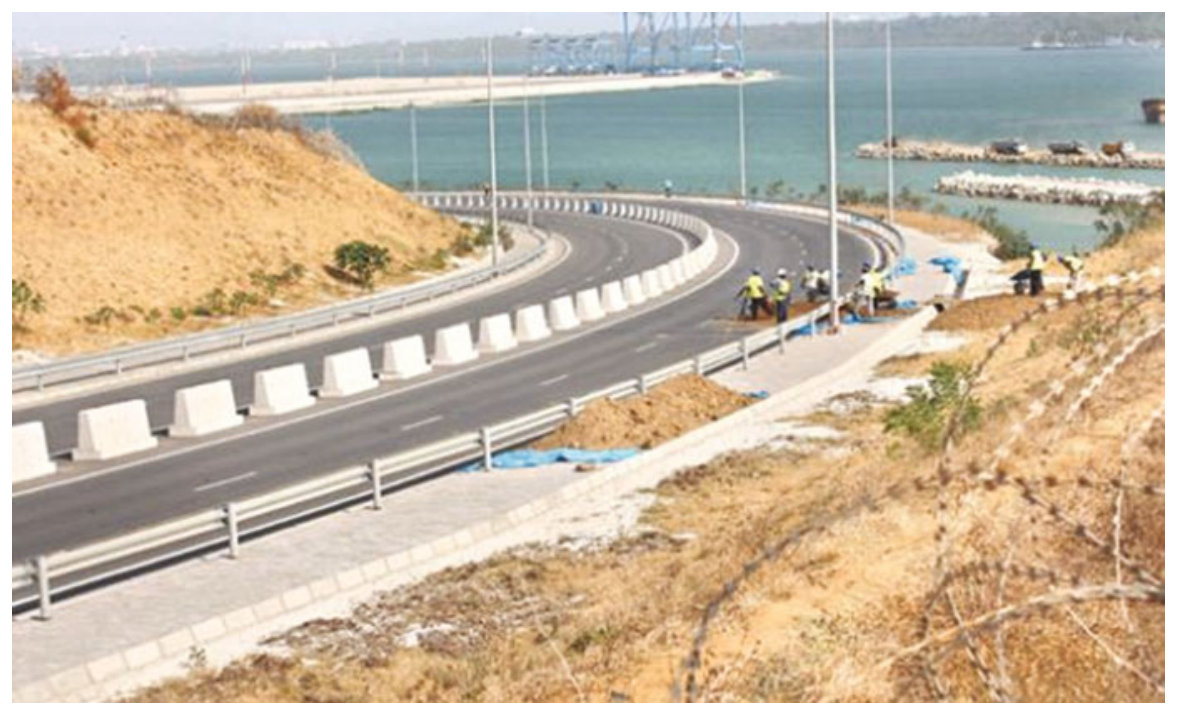

Fig. 5 The new Mombasa road by the seaside in Mombasa city

structures are recommended proactive measures for state and non-state entities to increase adaptation to climate change.

\section{Thika Superhighway Case Study}

The 8-lane highway project by the Kenyan Government was done to reduce congestion and increase connectivity between the capital city and the industrial town of Thika. Endless hours were spent in traffic to and from the city when the road was only two lanes. However, the problem of traffic congestion still persists.

The climate action plan recommends a mass transit system Bus Rapid Transit (BRT) complemented with a light rail as mitigation measure against climate change. This measure is estimated to abate approximately $2.8 \mathrm{MtCO}_{2}$ emissions by 2030 . At the moment there is a sharp increase in car ownership in Kenya. On average at least 20,000 cars are added to the Kenyan roads every month as illustrated in Fig. 6 majority of which are used in Nairobi metropolis.

The Government of Kenya is aiming to introduce BRTs in 2019 and has already marked dedicated lanes in the superhighway for the BRTs (see Fig. 7).

In addition, the Kenyan Government sought to introduce two car-free days every Wednesday and Saturday with the introduction of BRTs in 2019. These car-free days policy was dead on arrival due to lack of alternative means of transportation as the BRT is yet to arrive, and public consultation was not conducted. There has been wide resistance among the masses on the same leading to cancelation of the two car-free days (Okinda 2019; Ondieki 2019).

If the BRT system proves reliable in the long run, it will contribute to promoting sustainable transport and reduce emissions associated with personal car use. A major boost to mitigation efforts. 


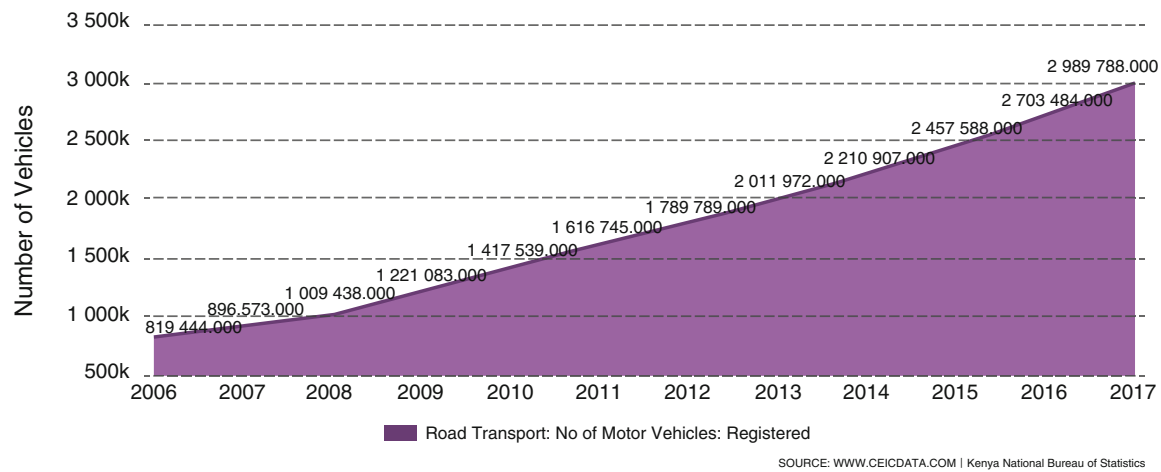

Fig. 6 Yearly number of motor vehicles registered in Kenya Road Transport. (Source: Kenya National bureau of Statistics)

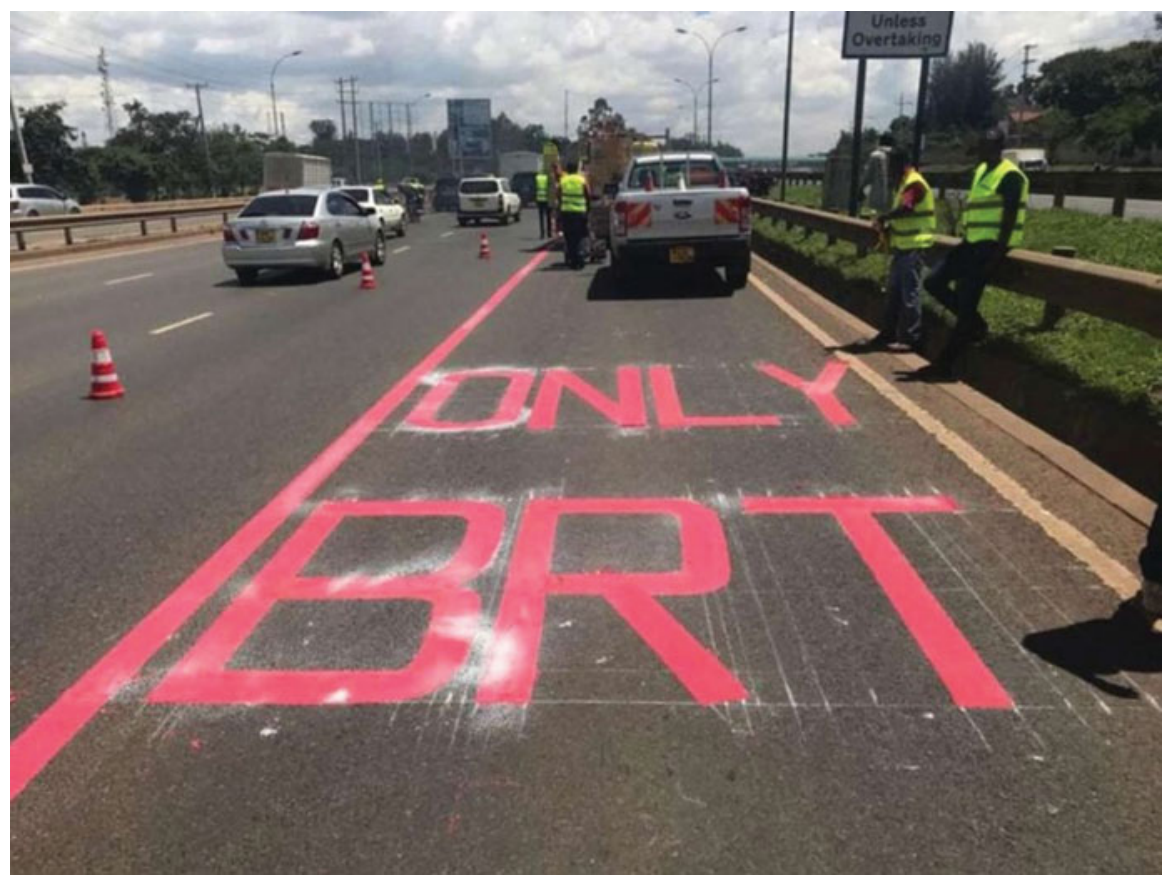

Fig. 7 Lanes marked on Thika superhighway for BRT buses to be introduced by the Kenyan Government in early 2019

Introduction of BRT will also enable decongestion of the city roads and reducing traffic snarl ups. Laudable mitigation efforts. Nonetheless, the transport infrastructure needs to adapt to climate change. This same superhighway with lanes marked for BRT has faced inundation challenges (see Fig. 8), as adaptation measures were not incorporated in design. The gray to green infrastructure is high, and future climatic predictions did not inform the design. Poor solid waste management 


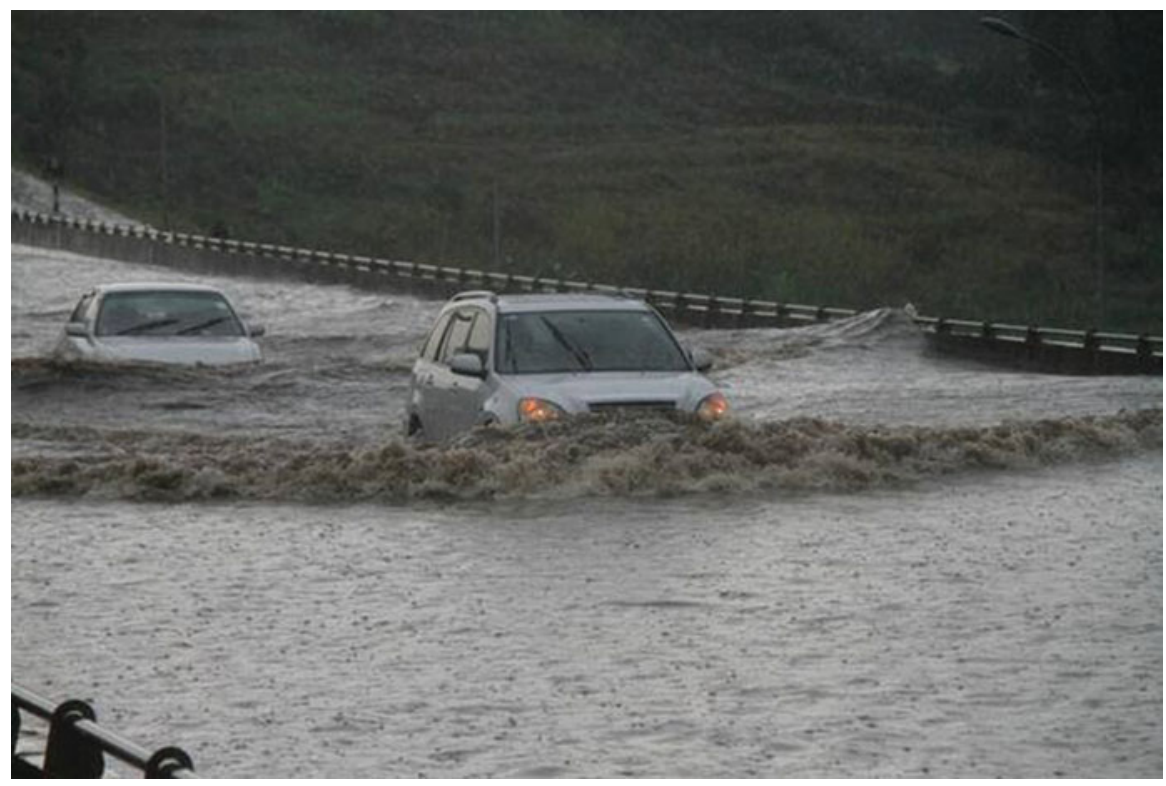

Fig. 8 A flooded Thika superhighway after a downpour

exacerbates the problem due to blocking of drainages. Without incorporating adaptation measures, mitigation measures laudable as they may be will soon become laughable as the climate changes and weather events become extreme.

The Government is currently constructing bypasses around the city to manage traffic as well as expanding city roads. This is a short-term solution as seen from Thika superhighway case. More road networks, more expansion, and more cars and BRT lanes adding to climate change. Any magnitude of rainfall even light showers causes unprecedented traffic snarl ups in all Nairobi city roads. One can only imagine how chaotic the scenario will be as the climate continues to change in an unpleasant manner. The impact that will have on the economy is big due to productivity losses as the human capital is wasted in traffic jams that also contribute to more carbon emissions - a double loss.

To adapt and mitigate accordingly the Government needs to implement policies that counter this positive feedback loop associated with road expansion or "reliable" transport. In the Thika road scenario after road expansion, settlement along the highway exploded. The population shifted to Thika roadside and mostly young people, with young families hence more and more cars on the road. Infrastructure in every aspect has been stretched, wastewater systems are strained, and sewage overflows are common and worse when it rains. Clean water supply to homes is increasingly inadequate as more apartments are added per mile. Adequate physical planning and dedicated implementation to guide human settlement will support mitigation measures and enhance adaptation. 


\section{Non-motor Transport}

Among the incremental investments required to ensure that all infrastructure developed is climate-resilient, Kenya's National Climate Change Action Plan envisions that bicycle lanes and sidewalks, to be developed in parallel with the transit system, will contribute to an emission reduction of $4.1 \mathrm{MtCO}_{2}$ of emissions by $2030(\mathrm{MoE}$ 2013).

New roads outside the central business district (including sections of Thika road) have cycling lanes; the old roads and those running through the central business district were not designed for cyclists as they lack cycling lanes. At some point a cyclist has to share a road with motorists as they make their way into the city. Cycling is a risky affair in most of Nairobi as motorists and cyclists have to share roads (see Figs. 9 and 10).

Cycling lanes are invaded by motorcycles that poorly observe road discipline. Pedestrians also leave sidewalks for cycling lanes. This fails to encourage uptake of non-motor transport in form of cycling.

This has not triggered nor supported a cycling culture. Besides cycling being viewed to be very risky, road discipline is very low for motorists and cyclists to share a road. The fact that the older roads were not designed for cyclists and lack of sufficient secure bicycle parking spaces indicates that local government leadership was not pro-cycling. The local government has banned public transport a couple of times which led to great inconvenience to commuters and the labor force. The idea

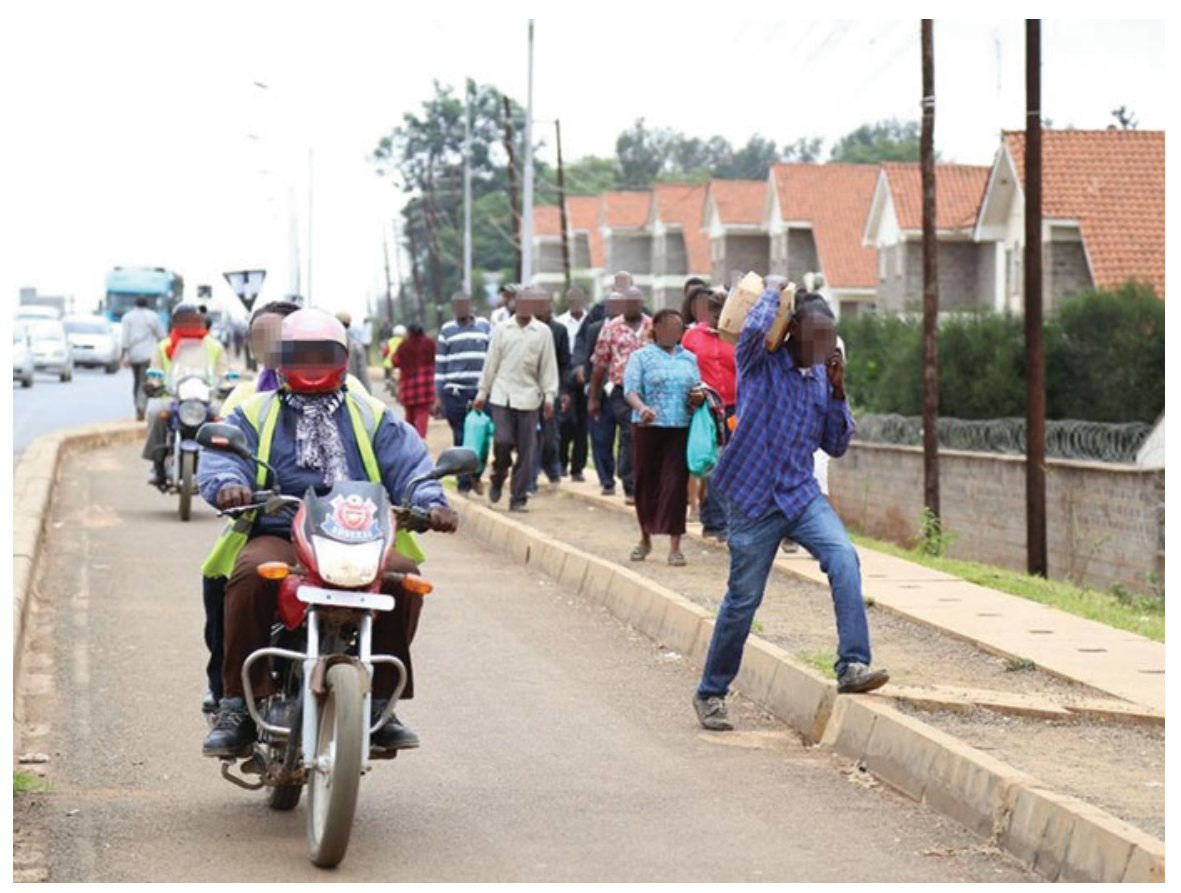

Fig. 9 Motorcycles using lanes designated for non-motor transport 
Fig. 10 Cyclist sharing a road with oncoming motorists

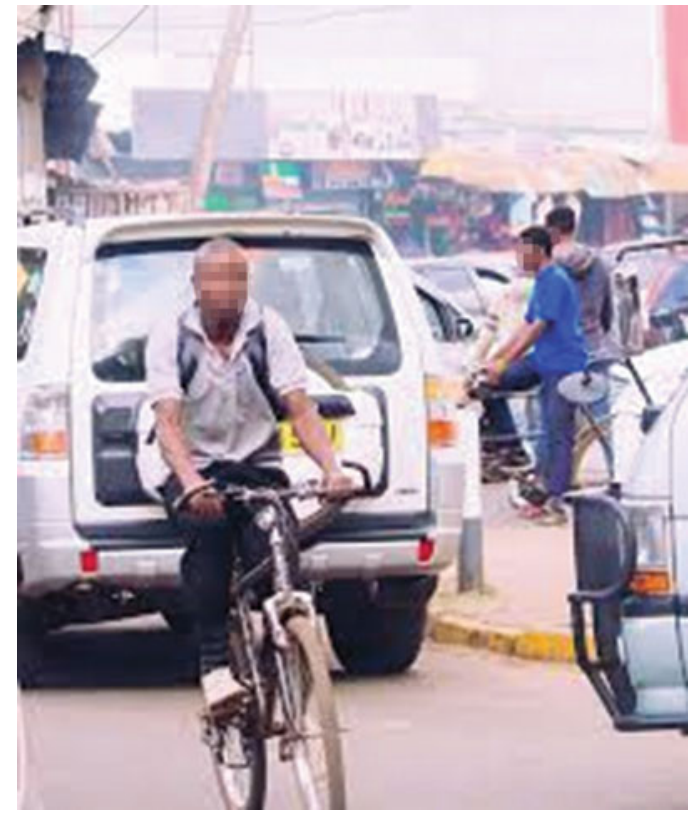

succumbed to lack of alternative means for connectivity. Not once did the local government introduce bike share program as an alternative transport mode. Majority of the buildings also do not have cloak rooms with public showers to encourage a "cycle to work" culture, lack of pro-cycling policies do not favor a cycling culture or thinking to thrive. Legislating a policy to make accessories in every building that will encourage sustainable living basic is recommended. The policy can have a percentage of parking spaces and rest rooms dedicated for secure bicycle parking spaces, shower, and changing rooms.

Negative perceptions to cycling greatly contribute to its adoption level. A study by Mitullah and Makajuma (2013) analyzing non-motorized travel conditions on the Jogoo Road corridor in Nairobi established that $66 \%$ of the participants expressed views that riding a bicycle shows that one is poor: $3 \%$ of these strongly agreed to this, $19 \%$ agreed to it, and $44 \%$ felt somehow riding a bicycle is an indication of poverty. Therefore, to shift to sustainable modes of transportation requires education of the masses and example setting by the leadership to help eliminate such perceptions. Politicians embracing non-motorized transport will manage perceptions usher attitude change and show political good will.

\section{Level of Integration of Climate Change Concerns in Design}

Temperature rise received the highest percentage in design consideration and material use as $53.8 \%$ of the respondents indicated. Anecdotally, following registered complaints from a number of occupants some new buildings are designed for a hot climate. During cold season they are very cold necessitating use of heaters which 
raises energy use that upsets the sustainability message. But in hot season they have excellent occupant comfort.

A large number of participants (61.5\%) indicated not giving high consideration to indoor climate in design aspects of a building. Water efficiency to improve water security was a high consideration to $38.5 \%$ of the participants and increased wind strengths was factored in design by $23.1 \%$ of the respondents.

Energy audit study jointly conducted by UN Habitat, University of Nairobi and Makerere established that buildings in East Africa designed before 1990 are more energy efficient while most of the buildings designed in the 90s are less energy efficient. This was attributed to abandoning of vernacular architecture for what is trending like glass building envelopes as they are aesthetically appealing without considering which materials the local environment supports or which materials support the local environment for occupant comfort.

\section{Integration of Climate Adaptation into Transport Infrastructure Projects}

Thirty-one percent (31\%) of study participants were very confident that culverts and stormwater drains can handle some percent increase inflow due to intense rainfall. Use of insurance schemes against flooding damages was reported by fifteen percent $(15 \%)$ of the respondents. Insuring of buildings against collapses was reported by twenty-three percent $(23 \%)$ of the participants.

\section{Conclusion}

There is less target action in mainstreaming climate change in the infrastructure sector in Kenya. Climate change integration in infrastructure construction is very low. Barriers to taking action include low accessibility of met data to industry professionals, lack of sector specific laws and policies enforcing mainstreaming, low awareness of adaptation and mitigation measures for infrastructure, and perceptions of sustainability as a soft and foreign concept.

Uptake of measures stated in the National Climate Change Action Plan is very low in the infrastructure sector. The measures need to have targets attached to them. A low carbon development pathway is within reach of developing countries if they embrace both adaptation and mitigation measures in matching strength. The infrastructure sector in Nairobi has low resilience to climate change. Physical planning inadequacies and weak complimentary policies are reinforcing these weaknesses enhancing the city's vulnerabilities.

Overall mitigation has better attention than adaptation (Fig. 11).

There is a need to balance the equation (as shown in Figure 11) for a robust and resilient outcome in growth and development.

Climate change adaptation and mitigation in cities should not be addressed in isolation; attention should be given to all sectors to manage interlinkages and interconnectivities. While pockets of leadership are witnessed through a project by project approach (tokenism), broad investment flows yield synergy that is more impactful, realize greater resilience, and harness robustness. 


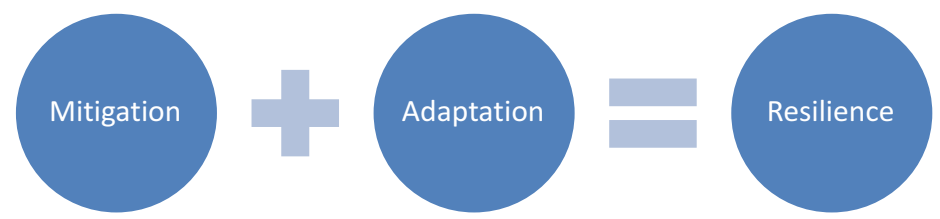

Fig. 11 Mitigation and adaptation need to be adopted in marching strength for climate resilience to be realized

\section{References}

Amboga R (2013) An investigation of urban heat island phenomenon in Nairobi. Unpublished manuscript. University of Nairobi

Dave M, Varshney A, Graham P (2016) Assessing the climate change adaptability of buildings. City Futures Research Centre, Sydney

Douglas I, Alam K, Maghenda M, Mcdonnell Y, McLean L, Campbell J (2008) Unjust waters: climate change, flooding and the urban poor in Africa. Environ Urban 20(1):187-205

Foster SSD, Tuinhof A (2005) The role of groundwater in the water supply of Greater Nairobi, Kenya. World Bank, GW-MATE Case Profile No 13

Government of Kenya, Ministry of Environment (MoE) (2010) National climate change response strategy executive brief

Government of Kenya, Ministry of Environment (MoE) (2013) National climate change action plan 2013-2017

Hope K (2012) Urbanisation in Kenya. Afr J Econ Sustain Dev 1:4. https://oi.org/10.1504/ AJESD.2012.045751

Klepeis NE, Nelson WC, Ott WR, Robinson JP, Tsang AM, Switzer P, ... Engelmann WH (2001) The National Human Activity Pattern Survey (NHAPS): a resource for assessing exposure to environmental pollutants. J Exposure Sci Environ Epidemiol 11(3):231

Makokha GL, Shisanya CA (2010) Trends in mean annual minimum and maximum near surface temperature in Nairobi City, Kenya. Adv Meteorol 2010

Mathu EM, Onyancha C, Mwea S, Ngecu W (2014) Effects of drilling deep tube wells in the urban areas of Nairobi city, Kenya. ARPN J Earth Sci 3(1):17-24

Mitullah W, Makajuma G (2013) Analysis of non-motorised travel conditions on the Jogoo Road corridor in Nairobi. Retrieved from: http://erepository.uonbi.ac.ke/bitstream/handle/11295/ 61279/Mitullah_Analysis $\% 2$ bof $\% 2$ bnon $\% 2$ bmotorised $\% 2$ btravel $\% 2$ bconditions.pdf? sequence $=$ 1 \&isAllowed $=\mathrm{y}$

National Construction Authority (2017) Research on building failures in Kenya. Unpublished manuscript

Nelson KC et al (2009) Forecasting the combined effects of urbanization and climate change of stream ecosystems: from impacts to management options. J Appl Ecol 46(1):154-163

Okinda B (2019) Nairobi announces car-free days as BRT plan shapes up. Monday January 28 2019. Retrieved from: https://www.nation.co.ke/news/Nairobi-finally-gets-car-free-days/10564955054-d42b8d/index.html

Olingo A (2011) Is your borehole water safe? Retrieved from: https://www.standardmedia.co.ke/ business/article/2000040134/is-your-borehole-water-safe

Ondieki E (2019) Kenyans oppose plan to have two car-free days in the city. Wednesday January 30 2019. Retrieved from: https://www.nation.co.ke/news/Kenyans-oppose-plan-to-have-two-carfree-days-in-the-city/1056-4957582-12urcjcz/index.html 
Onkangi RN, Njiiri MP, Maklago E, Lilian O (2019) Vulnerability and adaptation levels of the construction industry in Kenya to climate change. In: Leal FW (ed) Handbook of climate change resilience. Springer, Cham

Opijah FJ, Ng'ang'a JK, Omedo G, Mukabana JR (2008) Contribution to the heat budget in Nairobi-metro area by the anthropogenic heat component. J Kenya Meteorol Soc 2:1

Owiti SO (2016) Urban heat island: investiggation of urban heat island effect. A case study of Nairobi. Unpublished manuscript. University of Nairobi

Paris Agreement, 2015

Parry JE, Echeverria D, Dekens J, Maitima J (2012) Climate risks, vulnerability and governance in Kenya: a review. Commissioned by: Climate Risk Management Technical Assistance Support Project (CRM TASP), joint initiative of Bureau for Crisis Prevention and Recovery and Bureau for Development Policy of UNDP

Wilbanks TJ, Fernandez S (2014) Climate change and infrastructure, Urban Systems, and vulnerabilities: technical report for the US Department of Energy in support of the National Climate Assessment. Island Press, Washington, DC

Wilby RL (2007) A review of climate change impacts on the built environment. Built Environ 33:1 World Bank (2016) Kenya urbanization review. World Bank, Washington, DC. (C) World Bank. https://openknowledge.worldbank.org/handle/10986/23753. License: CC BY 3.0 IGO

Yigitcanlar T, Kamruzzaman M (2015) Planning, development and management of sustainable cities: a commentary from the guest editors. Sustain 7(11):14677-14688. https://doi.org/ $10.3390 / \mathrm{su} 71114677$

Open Access This chapter is licensed under the terms of the Creative Commons Attribution 4.0 International License (http://creativecommons.org/licenses/by/4.0/), which permits use, sharing, adaptation, distribution and reproduction in any medium or format, as long as you give appropriate credit to the original author(s) and the source, provide a link to the Creative Commons license and indicate if changes were made.

The images or other third party material in this chapter are included in the chapter's Creative Commons license, unless indicated otherwise in a credit line to the material. If material is not included in the chapter's Creative Commons license and your intended use is not permitted by statutory regulation or exceeds the permitted use, you will need to obtain permission directly from the copyright holder.

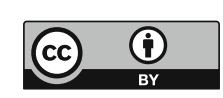

